\title{
Promoting Counterargument in Student's Argumentative Writing: A Dialogic Approach
}

\author{
Sueb \\ Universitas Negeri Surabaya \\ Surabaya, Indonesia \\ sueb@unesa.ac.id
}

\author{
Lina Purwaning Hartanti \\ Universitas Negeri Surabaya \\ Surabaya, Indonesia \\ linapurwaning@unesa.ac.id
}

\author{
Hujuala Rika Ayu \\ Universitas Negeri Surabaya \\ Surabaya, Indonesia \\ hujualarika@unesa.ac.id
}

\begin{abstract}
It is important for students to integrate both argument and counterargument to construct effective argumentative writing. One strategy believed to improve the effectiveness of student's argumentative writing is through the employment of Bakhtinian dialogism. This action research was intended to observe student's strategy in constructing argumentative essay in the undergraduate EFL classroom in terms of balanced integration of argumentation, counterargument, and refutation through dialogic approach during drafting. In addition, possible factors that affect student's strategy in constructing argumentative. The results show some student's hesitation to the use of counterargument in the writing despite the fact other features in the argumentative essay show good quality. Possible factors in writing process are also discussed, e.g. student's sociocultural background, English proficiency level, and also attitudes towards the dialogic approach. Some suggestions indicate that students should be more encouraged to apply counterarguments in their essay in a more practical approach.
\end{abstract}

Keywords-component; formatting; style; styling; insert (key words)

\section{INTRODUCTION}

Several instructional strategies have been employed to teach argumentative writing in undergraduate programs on English for academic purposes (EAP). One noticeable strategy used by English teachers in the writing classroom is the use of form-based approach (known as formalist approach), which generally follows five-paragraph essay structure. The employment of form-based approach into the teaching of argumentative writing has been proven to help students improve their argumentative writing as measured by standardized testing condition [1].

In terms of significance, however, this model of essay often fails to persuade the students to relate their writings to the social, ethic, and real world advocacy. In other world, students' writing is projected as test fulfillment instead of real world discourse.

Reflected with the $21^{\text {st }}$ Century skills as reported by World Economic Forum in 2016 on rethinking the education system emphasizing on both technical and social and analytical skills (The Future of Job Report, 2016) [2], the National Competence Platform for higher education in Indonesia (KKNI) which requires some skills including critical thinking, meaningful learning, and literacy competence should extend the target from test-based approach to real world issues and how students take part on the complex society. It is believed that alternative approach is needed to accommodate students to relate their learning activities, including writing argumentative essays, to the real world context. Regarding the trend, thus, the definition of argumentation as to support claim by providing cases should be broadened as well to become "as predictive of counterarguments accompanied by responses that are respectful of diverse views within a heterogeneous society" [3].

Due to the broader and emerging needs upon the trends, one of the alternative approaches to accommodate the students is through dialogic approach. A dialogic approach is believed to help students to understand and master complex literacy skills associated with argument talks and writings as well as participate in meaningful arguments within social contexts.

Researches on writing carried out by Hoey [4] and Thompson [5] assert that writing is principally a reciprocal dialogue between the authors and their readers. In relation with the argumentative writing, it is intended to communicate meaning to others by using various textual aspects such as statements, claims, reasoning, analyses, questions, conjunctions, and so forth to express advocacy of certain issues (which is obviously a dialogical process). An understanding of Bakhtinian dialogism is believed to equip students with the right concept in preparing the argumentative writing and utilize both side of argumentations to meet the argumentation genre [6]. 
This research is intended to elaborate the steps and procedures of promoting dialogic approach to accommodate counterarguments in argumentative writing process, particularly during drafting phase and student's perception on the use of dialogic activities in the writing activities.

\section{METHOD}

This is a mixed-method action research with sequential transformative research by employing action research which focuses on the implementation of dialogic approach in argumentative writing process. Twenty $(N=20)$ undergraduate students of one public university in Indonesia were involved in this integrated classroom activities such as dialogues (spoken) on given topics during the brainstorming and drafting sessions (written). Two topics were utilized for this action research, during the second-half of one academic semester (2 submissions of writings in 6 meetings).

Data collection was only on the classroom observation and classroom reflection. Classroom observation focused on how the procedures of utilizing dialogic approach in promoting counterarguments in the process of argumentative writing. The dialogic approach appeared mainly in the process of brainstorming to drafting. In these sessions, students were encouraged to share information with their peers, standing in opposing views from their peers during the discussion. This strategy was intended to construct more points from diverse views covering both sides, pros and cons. For classroom reflection, the students were invited to provide feedback led by the teacher upon what they have done during the dialogic process as well as how they perceived the dialogic process towards their counterarguments in the argumentative writing.

As it is an ongoing research, further studies are still needed to elaborate how students utilized counterargument strategies instead of one-sided argumentative writing and students employed more substantial premises in their argumentative writings.

\section{FINDINGS AND DISCUSSION}

This section discusses two main sections, namely the procedures on accommodating the dialogic approach as a means to promote the counterarguments in the process of writing argumentative essay. Secondly, classroom reflection was conducted in order to internalize the dialogic process as part of argumentative writing process. Each section presents both practical and theoretical bases upon the implementation of dialogic approach to promote counterarguments in argumentative essays.

\section{A. Procedures on promoting counterarguments through dialogic approach}

The implementation of dialogism approach in learning argumentation uses exemplary lesson structure, which consists of several parts, namely present, practice, and produce. This learning structure is basically almost the same as the learning structure in general, namely pre-activities, core activities, and closing. The following are the detail elaboration of each session:

- Preparation. The whole class was divided into two big groups and provided with one controversial topic about education. They were assigned to take stance, one for affirmative group which was to support the topic while the other group was against the topic. This division with clear stance allowed students to think focusing on their stance, either to support or against the topic.

- Brainstorming. Students were given 10 minutes to brainstorm about the topic and encouraged to construct possible cases from the topic. The case of the topic becomes the general objective that should be supported with some arguments. In other words, the case of the topic would become the thesis statement for their writing. The arguments are expected to be derived from several perspectives during the brainstorming session.

In this session, students are invited to express their views related to the topic being discussed. The ideas conveyed do not have to originate from the writing, but rather from the general understanding that students have. Such activity is intended to accommodate two main aspects, namely measuring students' understanding on the topic as well as students' interest related to the issue being discussed. Thus, teacher should take the choice of topic into account by understanding the students' background and attitudes through the discussion.

Regarding the choice of the topic, the selected topics discussed in the classroom should consider several aspects including student background, trend and updated issues, and the relationship of topics to students. Teachers may conduct pre-activity survey intended to shortlist appropriate topics in the classroom. Considering that this research was conducted on students who attend English Education courses, for example, topic selection could begin with issues surrounding foreign language learning or education, followed by a hot topic among students namely pop culture, fashion, entertainment, to the more complex ones such as the use of electronic money (e-money) and environment. Complex and sensitive topics such as socio-politics and religion might inhibit students' engagement and critical thinking in the classroom, which means it may require better preparation and guidance in order to create safe and comfortable environment for the students without losing the essence of critical discussion [9].

During the brainstorming process, students seemed to respond in turn. In general, students' active participation was an indicator that the topic used is acceptable and not an obstacle. In this condition, teacher is encouraged to facilitate the dynamics of classroom discussion as well as critical discussion in order to obtain as much as information which would be beneficial for the writing. 
- Question prompts. There are several strategies that can be utilized by the teachers to accommodate present sessions, especially brainstorming, namely by presenting several questions that may encourage students to participate into further and deeper discussion (question prompts). Such prompts would be useful in order to allow students generate more knowledge and information, which is good for the process of writing. The question prompts used to build students' understanding in argumentative writing context should be balanced covering both parties, both pros and cons. There are two reasons why it must be balanced, namely to focus on the purpose of discussion for argumentation learning and to provide space for students to understand an issue from two perspectives. This rationale becomes the core of dialogism, which in turn allow students to even build counterarguments and predict possible responses from the arguments or the counterarguments.

In relation with the brainstorming session in argumentative writing classroom and the use of question prompts during the process, there are some aspects that should be considered in order to utilize the questions effectively, like ensuring the questions are open (not yes-no questions), questions which encourage the students to deliver longer answer and analyses (typical why-questions). Such questions may provide space for members to present ideas and creativity freely and avoid questions that deviate from focus or expectations of participants [7], which is again in line with the core of dialogism which covers both sides of discussion.

- Practice. This session took place after the brainstorm session had been finished or considered to have provided sufficient information for further language production such as writing argumentations. Practice was mainly in the form of student dialogues on the topic being discussed in smaller group, allowing the students to start focusing on their topic and writing the essay.

In this session, the conception of dialogism should be accommodated carefully by the teachers as to recognize the multiplicity of perspectives and voices, which can become as double-voiced or multi-voiced perspectives. A dialogical activity in argumentative writing session constantly engages with and is informed by other arguments, and seeking to counter or inform it. Everything is said in response to other statements and in anticipation of the upcoming statements. Teachers should be aware with any responses and accommodative towards these statements.

At the end of this session, the students were divided into several small groups that discuss the arguments, counter-arguments, and predictions of responses that will arise over the counter-arguments they provide. The students were asked to map the structure of writing based on several aspects in general, namely the background of the problem in writing, the case discussed, their points to support the case or thesis statement, the statements from their peers, and possible responses to their peer's statements.

In general, the students were asked to work on worksheets that were able to facilitate the students have dialogues with their peers, exchanging ideas from the selected topic. Students were not determined in which side they will take (taking stance) during the process of dialogues, but were asked to complete information related to the existing arguments by having deeper discussion and idea exchanges with their colleagues. Based on the task structure, students were invited to complete information as they expected. Students were encouraged to dare to determine a different stance with their peers so that the inquiry becomes richer through dialogues [9].

In this session, the role of the teachers should walk around counseling the students and providing encouragement and assistance to certain groups in accordance with their progress. Teachers may also throw some questions in the middle of the discussion without distracting the focus of the dialogue being held within the group members.

- Drafting. At the end of the class session, students were asked to determine their stance and start developing an outline or drafting based on information obtained during the dialogue session with their peers. Students were given the freedom to determine the party (stance) on the topic being discussed, whether standing on the pros or cons. Students would collect draft arguments on certain predetermined deadlines and will be discussed at the next meeting. Drafting is supposedly integrated into practice session; it is a language productive phase where students may need longer time, both to synthesize their idea and juxtapose information obtained from the dialogues.

\section{B. Reflection on the use of dialogic approach for argumentative writing}

After submission, students were invited to reflect what they have done throughout the process, from brainstorming, discussing (dialoguing), practicing, and drafting. The reflection was conducted in semi-formal sharing session at the end of the class. There are some aspects as the focus of the reflection, namely students' perception towards dialogue process on their writing process, their language production, and content aspect. In general, students show positive reflection and believe that dialogues helped them have intensive collaboration write longer with more diverse perspectives in their argumentative essay. As this is an ongoing research, analytical study is needed to present the detail direct correlation between dialogue activities with the quality of argumentative writing.

They believe that they had sufficient information obtained from the dialogues. In addition, students perceive the dialogue process allowed them to engage in collaborative writing process [10], predicting the opposing view, which is good for 
them to set certain strategy by constructing counterview. This indicates students employ both sides in their writing and accommodate diverse perspective, which is to strengthen the quality of argumentative writing.

In addition, as it was indicated from students' argumentative essays which mentioned more points or arguments, students concluded that they obtained more points during the classroom brainstorming and group discussion. One student claimed as follows:

Every time my peer said his point, I felt I had to give response from different perspective. I was encouraged to counter what he said $[\ldots]$ helping me to have more points from both sides. If I support the topic, I'd use my points to support the topic and target my friend's points in the form of rebuttals.

Without being informed what they have done in the writing was actually counterarguments, students asserted that they targeted what their peer's points, indicating they observed and predict their peer's arguments as their basis of the counterarguments. In short, dialogic process allowed them to obtain more points both pros and cons upon the topic; students would utilize their points to support the topic, while they at the same time utilized their peer's points as the targeted points in the form of counterarguments. This thinking strategy would lead into more comprehensive argument-counterargument style in the argumentative writing as well as provide them with more premises which can be developed into more arguments.

\section{CONCLUSION}

Based on the classroom observation and reflection in the study, some conclusions were obtained. First, students experienced a more collaborative learning process in the form of discussion from different perspectives (dialogues) in their argumentative writing which is believed to give them more opportunity to gain more ideas. The activities include brainstorming session, peer discussion, and drafting. Secondly, students were able to have balanced information from the topics discussed. This is considered important as the initial capital for writing strong arguments to accommodate a variety of different perspectives (dialogical), not just in one direction only (monological). Additionally, students perceived that the idea of dialogism occurred naturally and did not place a direct burden to them during the classroom brainstorming and peer discussion. On the other hand, this approach could provide comprehensive information needed by the students in their argumentative writing.

Some recommended actions needed in optimizing this research, namely the need for an alternative approach in learning argumentation, from a formalist approach (which emphasizes structure) with an approach that emphasizes the process of dialogue. Action research is needed to observe the significance of the intervention to the quality argumentative writing in advocating for real issues so as to produce more meaningful writing.

\section{ACKNOWLEDGMENT}

This study is supported by the institutional-grant for faculty members as part of the program to establish policy in learning practices at the university. The funding is provided by Faculty of Languages and Arts, State University of Surabaya.

\section{REFERENCES}

[1] Nussbaum, Michael \& Schraw, Gregory. (2007). Promoting ArgumentCounterargument Integration in Students' Writing. Journal of Experimental Education, 59-92. 10.3200/JEXE.76.1.59-92.

[2] World Economic Forum. (2016). The Future of Jobs Employment, Skills and Workforce Strategy for the Fourth Industrial Revolution.

[3] VanDerHeide, Jennifer \& Juzwik, Mary \& Dunn, Mandie. (2016). Teaching and Learning Argumentation in English: A Dialogic Approach. Theory Into Practice. 55. 10.1080/00405841.2016.1208069.

[4] Hoey, M. (2001) Textual Interaction: An Introduction to Written Discourse Analysis. London: Routledge.

[5] Thompson, G. (2001). Interaction in academic writing: learning to argue with the reader. Applied Linguistics 22(1): 58-78.

[6] Bakhtin, M. M. (1986). The Problem of Speech Genres. C. Emerson \& Holquist, M. (Eds.), Speech Genres and Other Late Essays (pp. 60-102). Austin: University of Texas Press.

[7] Gregersen, H. 2018. Better Brainstorming. Harvard Business Review March-April 2018 Issue.

[8] Maulidah, Nova et. al. (2013). Think-Talk-Write (TTW) Strategy for Teaching Descriptive Writing. Jurnal Pendidikan Bahasa Inggris STKIP PGRI Sidoarjo 1 (1), 48-58

[9] Pace, D. (2003). Controlled Fission: Teaching Supercharged Subjects. College Teaching, 51(2), 42-45. Retrieved from www.jstor.org/stable/27559130

[10] Storch, N. 2002. Patterns of interaction in ESL pair work. Language Learning, 52(1), 119- 158.1 